\title{
New trends and perspectives in hepatobiliary surgery: preface
}

It is our great pleasure to introduce the focused issue entitled: "New trends and perspectives in hepatobiliary surgery". Great evolutions have been recently introduced in the field of hepatobiliary surgery, strongly increasing our ability to manage challenging pathologies involving the liver.

In the present issue we report the most recent innovations for the surgical management of hepatic tumors. Centers coming from Western and Eastern world have been involved to discuss these novelties.

As for the management of colorectal metastases, we asked Abbasi et al. (US) to introduce the "Role of associating liver partition and portal vein ligation in staged hepatectomy (ALPPS)—strategy for colorectal liver metastases" (1). Andres et al. (Switzerland) reported the growing interest of the scientific community on "Transplantation for colorectal metastases: on the edge of a revolution" (2).

Another liver tumor analysed in this issue has been the cholangiocellular cancer. Two important contributions have been reported on this tumor, namely the study by Waisberg et al. (Brazil), focused on the "Resection for intrahepatic cholangiocellular cancer: new advances" (3), and the paper by Capobianco et al. (Germany), on the "Resection for Klatskin tumors: technical complexities and results" (4).

Particular attention has been placed for the evolutions observed in terms of the management of hepatocellular cancer. Giovanardi et al. and Lai et al. (Italy) focused their attention on the different roles of "Resection for hepatocellular cancer: overpassing old barriers" (5) and "Transplantation for hepatocellular cancer: pushing to the limits?" (6).

Di Sandro et al. (Italy) in detail elucidated "The current role of laparoscopic resection for HCC: a systematic review of past ten years" (7). Zheng et al. (China) very well summarized the place of the "Salvage liver transplant for hepatocellular carcinoma: rescues and benefits" (8). Angelico et al. (Italy) described the specific clinical condition of the "Hepatocellular carcinoma in children: hepatic resection and liver transplantation" (9).

Lastly, we are honoured to have had Prof. Lerut among the participants of this issue, presenting his study entitled "Vascular tumours of the liver: a particular story" (10).

We are glad the present issue has been realized thanks to the extraordinary efforts of so many experts coming from several different countries all around the world. We thank all of them for their contributions.

\section{Acknowledgements}

None.

\section{References}

1. Abbasi A, Rahnemai-Azar AA, Merath K, et al. Role of associating liver partition and portal vein ligation in staged hepatectomy (ALPPS)—strategy for colorectal liver metastases. Transl Gastroenterol Hepatol 2018;3:66.

2. Andres A, Oldani G, Berney T, et al. Transplantation for colorectal metastases: on the edge of a revolution. Transl Gastroenterol Hepatol 2018;3:74.

3. Waisberg DR, Pinheiro RS, Nacif LS, et al. Resection for intrahepatic cholangiocellular cancer: new advances. Transl Gastroenterol Hepatol 2018;3:60.

4. Capobianco I, Rolinger J, Nadalin S. Resection for Klatskin tumors: technical complexities and results. Transl Gastroenterol Hepatol 2018;3:69.

5. Giovanardi F, Lai Q, Bertacco A, et al. Resection for hepatocellular cancer: overpassing old barriers. Transl Gastroenterol Hepatol 2018;3:64.

6. Lai Q, Vitale A. Transplantation for hepatocellular cancer: pushing to the limits? Transl Gastroenterol Hepatol 2018;3:61.

7. Di Sandro S, Danieli M, Ferla F, et al. The current role of laparoscopic resection for HCC: a systematic review of past ten years. Transl Gastroenterol Hepatol 2018;3:68. 
8. Zheng S, Xie Q, Cheng J. Salvage liver transplant for hepatocellular carcinoma: rescues and benefits. Transl Gastroenterol Hepatol 2018;3:65.

9. Angelico R, Grimaldi C, Saffioti MC, et al. Hepatocellular carcinoma in children: hepatic resection and liver transplantation. Transl Gastroenterol Hepatol 2018;3:59.

10. Lerut J, Iesari S. Vascular tumours of the liver: a particular story. Transl Gastroenterol Hepatol 2018;3:62.

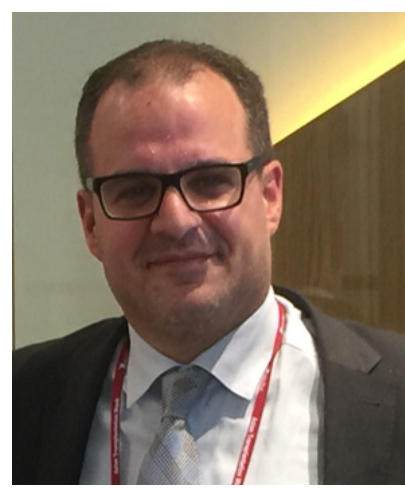

Alessandro Vitale

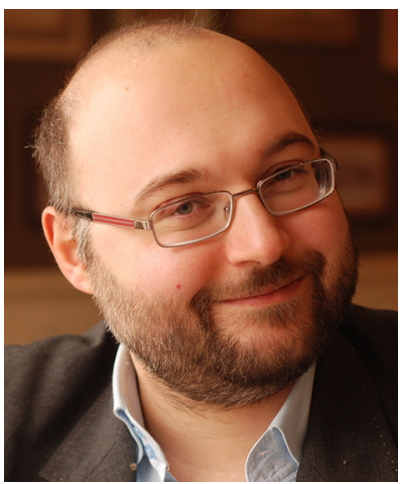

Quirino Lai

Alessandro Vitale, $\mathrm{MD}, \mathrm{PhD}$ Department of Surgery, Oncology and Gastroenterology, Padua University, Padua, Italy. (Email: alessandro.vitale@unipd.it) Quirino Lai, MD, PhD General Surgery and Organ Transplantation Unit, Department of Surgery, Sapienza University of Rome, Rome, Italy. (Email: lai.quirino@libero.it) doi: $10.21037 / \operatorname{tgh} .2018 .11 .06$ Conflicts of Interest: The authors have no conflicts of interest to declare.

View this article at: http://dx.doi.org/10.21037/tgh.2018.11.06

doi: $10.21037 / \operatorname{tgh} .2018 .11 .06$

Cite this article as: Vitale A, Lai Q. New trends and perspectives in hepatobiliary surgery: preface. Transl Gastroenterol Hepatol 2018;3:99. 